\title{
Modos de composição em artes presenciais: políticas inventivas nas ações modulares do coletivo Mapas e Hipertextos
}

Modes of composing in performing arts: inventive policies in Mapas e Hipertextos' modular actions

Milene Lopes Duenha ${ }^{1}$

Paloma Bianchi

Raquel Purper ${ }^{3}$ 


\section{Resumo}

Políticas de relação e política como tema: como articular os dois entendimentos de política em ações artísticas que se encontram alicerçadas pela noção de invenção? O que aparece primeiro no processo de composição em artes presenciais: o significado que permite a ampliação para os sentidos, ou os procedimentos que experienciam sentidos diversos e os convergem em significado? Questões como essas norteiam a escrita deste artigo que apresenta alguns relatos e conexões advindos de experiências compositivas desenvolvidas pelo Mapas e Hipertextos, coletivo de pesquisa e criação, sediado em Florianópolis-SC. Algumas pistas se revelam na trama entre teorias de pesquisadores como Bruno Latour e Virgínia Kastrup e descrições de experiências de integrantes do coletivo durante o processo de desenvolvimento de duas ações modulares que integram o trabalho intitulado Sem Cabimento (2015).

Palavras-chave: Política; invenção; emergência

\section{Abstract}

Policy relations and politics as a theme: how to articulate those political understandings in artistic actions that are embedded by the notion of invention? What appears first in the performing arts' composing process: the meaning that spread itself to create senses, or the procedures that produce different senses converging into meaning? Inquires like these guide this article to present some narratives and connections from the composing experiences developed by Mapas e Hipertextos, a collective dedicated to the research and creation in performing arts, based in Florianópolis-SC. Some clues are revealed in the plot between theories of researchers as Bruno Latour, Virginia Kastrup and Jacques Rancière and collective members' descriptions of the experience during the process of developing two modular actions that integrate the work entitled Sem Cabimento (2015).

Keywords: Policy; invention; emergence

ISSN: 1414.5731

E-ISSN: 2358.6958

1 Doutoranda no Programa de Pós-Graduação em Teatro (PPGT), da Universidade do Estado de Santa Catarina (UDESC). Atriz, bailarina e performer. miduenha@yahoo.com.br

2 Doutoranda no Programa de Pós-Graduação em Teatro (PPGT), da Universidade do Estado de Santa Catarina (UDESC). Bailarina, professora e pesquisadora. bianchi.paloma@gmail.com

3 Doutoranda no Programa de Pós-Graduação em Teatro (PPGT), da Universidade do Estado de Santa Catarina (UDESC). raquelita0406@gmail.com 
Somos um coletivo, lugar (sem lugar) que inventamos para investigar/fazer arte de um modo mais conectado com o mundo, menos sujeito ao mercado e com um tipo de produção advindo de um processo de fusão de linguagens que não cabe nos moldes de muitos festivais e editais de teatro ou de dança no Brasil. Habitamos um terreno movediço, mutante e provocativo. O produto é um tanto esquizofrênico, assim como a experiência profissional de seus integrantes com distintas formações. Trabalham juntas a bailarina, a coreógrafa, a atriz, a salva-vidas, a professora de dança contemporânea, a professora de inglês, a performer, a fotógrafa, a jornalista, a educadora de movimento, o designer, a recreadora, a cientista social, a doutoranda, a mestranda, a ativista, todos, porém, artistas. Assim, compomos um grupo de pesquisa em artes presenciais que acolhe as inquietações artísticas de seus integrantes em um processo que não hierarquiza seus elementos, e que resulta em algo que não é espetáculo, não é performance como se conhece nas artes visuais, mas é arte, dessas que buscam acontecimento, e que se faz no encontro com o outro. O público é agente, participa no processo de mapeamento e de construção, e também se torna cúmplice nos momentos em que a ação artística é posta em relação.

Neste artigo abordamos o modo de funcionamento do coletivo de pesquisa em artes presenciais Mapas e Hipertextos, apresentando uma pequena parte do nosso processo em um momento em que duas integrantes lançaram suas pesquisas acadêmico-artísticas ao grupo com o objetivo de testar ideias e extrair elementos para suas investigações. Este escrito se restringirá à discussão de duas ações: a ação modular do elástico, conduzida por Paloma Bianchi, e a ação modular da mão esquerda, orientada por Raquel Purper, desenvolvidas ao longo do ano de 2015 e que compõem o trabalho intitulado Sem Cabimento.

\section{O coletivo Mapas e Hipertextos}

Em agosto de 2012, o Mapas e Hipertextos começou como um projeto no qual duas discentes da pós-graduação em teatro da UDESC experimentavam combinar suas pesquisas acadêmicas: a site especificidade e a presença não impositiva do artista. Durante um ano, essas artistas-pesquisadoras criaram algumas estratégias de mapeamento e modos de composição ${ }^{4}$ ao observarem temas recorrentes no mundo virtual e em saídas de estudo pelas ruas de Florianópolis-SC. Alguns desses procedimentos de mapeamento consistiam na identificação de modos de imposição de poder e sua eficácia ante seu público-alvo, os cidadãos. Também procuravam encontrar estratégias de subversão dos comportamentos decorrentes de tal sujeição a esse sistema de imposição de poder. Os experimentos aconteciam por meio de diferentes suportes, na intenção de relacioná-los conforme a pesquisa fosse se desenvolvendo. Às fotografias e aos vídeos das incursões de mapeamento somavam-se ainda dados e imagens pesquisadas na internet. Da reunião desse material desenvolvíamos fragmentos compositivos contextuais, ou seja, ações modulares que incluíam o entorno, que tentavam subverter as lógicas de hierarquização e de subjetivação (inclusive do campo da arte). Tais ações eram levadas a público de diferentes maneiras: em performances ao vivo, em exibições de vídeo em eventos (encontros, festivais, etc.) e em divulgações de imagens e ações no meio virtual. 
Entre 2013 e 2014, outras cinco artistas se juntaram ao coletivo, também trazendo consigo suas pesquisas, aderindo a algumas estratégias de funcionamento e inaugurando outras. Assim, pesquisas que investigam a corporeidade política; noções de eficácia e fracasso no teatro na rua; presença/ausência; composição em dança e performance contemporâneas; relações entre espaço virtual e estrutura social; relações entre ética e estética; site specific; e processos de criação em arte como modo de subversão, configuraram o espectro investigativo do coletivo. O Mapas e Hipertextos, ao acolher as investigações/inquietações de cada artista, cria uma trama entre elementos e estratégias diversas que delineia o perfil do grupo como uma comunidade em que todos tomam parte (assumem sua parcela de responsabilidade) na intenção de chegar a um comum (Rancière, 2005), acolhendo inclusive o dissenso ${ }^{5}$.

Elegemos duas noções de política como recorte para a análise do processo desenvolvido no coletivo Mapas e Hipertextos: a política entendida como o modo como as relações se estabelecem; e a política como tema relacionado à ideia de representatividade, mais especificamente o contexto do poder político federativo brasileiro. O antropólogo, sociólogo e filósofo da ciência francês Bruno Latour (2004, p. 383) distingue três modos de abordagem da noção de política: uma como "a luta e os compromissos dos interesses e das paixões humanas diante das preocupações dos não-humanos", referindo-se a uma ideia de política da caverna, uma política-poder, que manteria a possibilidade de uma diferenciação - alguém que teria acesso à luz e não somente às sombras projetadas na caverna, aludindo à filosofia de Platão; outra como a "composição progressiva do mundo comum e todas as competências exercidas pelo coletivo"; e outra, ainda, como um dos elementos constituintes das relações sociais "pela ativação, sempre a retomar, da relação um/todos". Tomamos essas duas últimas acepções de política de Latour como dados de uma relação mais democrática que levaria em conta o coletivo, e a primeira acepção, a política-poder, como um tema problematizado nos modos de convívio e na produção artística emergente desses questionamentos. Latour (2004, p. 39) sugere a oposição entre a "política poder, herdeira da Caverna, e a política concebida como composição progressiva do mundo comum". Assim, expomos a evidência de algumas noções de política no processo desenvolvido no coletivo Mapas e Hipertextos, uma relacionada ao tema e ao desenho de procedimentos inventivos, e outra relacionada aos modos de estabelecimento das relações no próprio grupo e com o público, ambas contaminando o conteúdo poético.

No Mapas e Hipertextos não existe o desejo de criação de espetáculos com estrutura fechada. Pelo contrário, o coletivo se dedica à invenção de estruturas móveis que possam dar sustentação a um trabalho poroso como potência de afeto (Espinosa, 1992), quer seja em ambiente fechado, quer seja na rua, de modo que artista e público vivenciem uma possibilidade de transformação no ato de encontro entre os corpos. O nome Mapas e Hipertextos advém exatamente desse contexto. Mapas,

\footnotetext{
${ }^{4}$ A palavra composição é entendida aqui como possibilidade de se com-por, ou seja, pôr com o outro na arte, revelando-se como uma prática coletiva que tem por finalidade potencializar as relações, assim como o definem a antropóloga brasileira Fernanda Eugenio e o coreógrafo português João Fiadeiro (2012). Diferentemente do entendimento habitual de composição, nas artes presenciais essa ideia não se pauta na vontade de compor para mostrar, mas de compor diante dos afetos mútuos, buscando modos de provocar fissuras na percepção de quem se envolve.

5 "Dissenso" provém do verbo latino "dissero" (examinar, discutir uma matéria), que se transforma no substantivo dissensus. Segundo Alberto Buela (2011), significa outro sentido, divergência, parecer contrário, desacordo.
} 
pois partimos da interação com o entorno, por meio de mapeamentos materiais ou imateriais, para que o trabalho seja sempre contextual (Schiocchet, 2015). E Hipertextos diz respeito à noção de uma narrativa não sequencial que possibilita diferentes percursos, criando associações "aparentemente desconexas sem qualquer linearidade espacial ou temporal" (Schiocchet, 2015, p. 168). A pesquisadora e integrante do Mapas e Hipertextos Michele Schiocchet (2015) afirma que esse modo de organização propicia tanto a desierarquização entre os elementos do trabalho, pois estes funcionariam por proximidade e não por linearidade, quanto a horizontalização entre artista e público, já que o acesso e a articulação entre os conteúdos não são dados a priori, mas estão em constante construção e renegociação.

Como pesquisadoras e criadoras em arte, entendemos que as instâncias que compõem o fazer das artes presenciais - treinamento e criação - não podem se desassociar e devem ser contempladas tanto nos processos de pesquisa como nas ações artísticas em uma dupla perspectiva: tanto o treinamento deve estar em consonância com a criação a fim de que o processo criativo se constitua a partir dos modos de treinarmos, quanto os temas escolhidos para criação devem ser contemplados nos procedimentos de treinamento. Esse modo de operar viabiliza a composição entre cada uma das propostas, ampliando suas potencialidades, ao mesmo tempo que apresenta desafios enormes e requer ajustes constantes. A política de funcionamento do grupo é horizontal e não hierarquizada, embora haja uma organização que se mantém ao longo dos encontros. De modo geral, duas artistas ficam responsáveis pela gerência dos ensaios por um determinado período de tempo. A gerência, nesse contexto, se responsabiliza por trazer uma proposta de procedimento que tenha a ver com aquilo que interessa a elas investigar naquele momento. A proposta é colocada em prática durante alguns encontros, até que dela se possa identificar uma estrutura mais consistente que viabiliza a produção de ações modulares. A partir desse momento, o procedimento passa a ser gerido por todas do coletivo, sofrendo transformações substanciais.

Ações modulares são estruturas de ações relativamente abertas e independentes que podem ser combinadas e recombinadas de acordo com os contextos espaçotemporais, com o intuito de gerar novas configurações compositivas e performativas a cada apresentação. Assim, podemos alterar a ordem das ações, podemos inserir e suprimir alguma ação em particular, ou podemos transformar o sentido de uma ação específica ao mantermos somente sua estrutura.

As duas ações modulares que trazemos para discussão neste artigo possuem uma característica em comum: nunca foram experimentadas no ambiente urbano. Mas existe algo que as diferencia sobremaneira: suas políticas de invenção. A ação modular do elástico foi produzida a partir da experiência com a materialidade de um objeto: quatro elásticos com cerca de um metro e meio de comprimento que conectam os corpos das artistas. Tal procedimento gera uma política de relações e negociações específicas do movimento no aqui-agora do encontro no jogo entre a ação da gravidade, a resistência e a desistência, permitindo a emergência de sentidos e possíveis significados ${ }^{6}$. A ação modular da mão esquerda foi criada a partir de uma frase repleta de significado que serviu de impulso para o desenvolvimento de determinados movimentos e jogos de relação, cujos sentidos emergiriam nas experi- 
mentações entre as artistas e, posteriormente, na relação com o público interlocutor, configurando outro modo de operação exigente de outra política de relações. Não se trata aqui de uma diferenciação por juízo de valor, com finalidade de provar mais ou menos eficácia em cada procedimento, mas de uma observação de distintas políticas inventivas, geradoras de políticas relacionais específicas na composição e produção de experiência em artes presenciais.

Ao realizar um estudo sobre a atenção, a pesquisadora e psicóloga carioca Virginia Kastrup (2007) considera a possibilidade de uma cognição inventiva, afirmando que a arte teria o papel de criar fissuras perceptivas que provocariam novos caminhos para o aprendizado e para os processos de atenção. A cognição, segundo a autora (2007), já contém tanto a tendência de criar o novo quanto a tendência de se repetir: “Ela é, em seu fundo, criação e também indeterminação, imprevisibilidade" (p. 59). A cognição também possui por base uma inventividade intrínseca, ela é, por natureza, um processo inventivo que perdura no tempo e, justamente por ter duração, cria estruturas. Estruturas que, por sua vez, também são imprevisíveis. Kastrup (2007) afirma ainda que a fissura perceptiva, o Breakdown, é o que poderia ativar essa cognição inventiva, pois ao se vivenciar uma quebra no fluxo perceptivo somos obrigados a inventar novos caminhos.

Para Kastrup (2007), criatividade e invenção são termos distintos, pois a criatividade estaria mais próxima da capacidade de resolução de um problema dado, enquanto a invenção estaria mais próxima da capacidade de, além de resolver um problema, inventar problema. A invenção deriva da palavra invenire, que em latim diz respeito ao trabalho com relíquias ou com restos arqueológicos. Um trabalho que se dá pela experimentação em duração: a invenção implica o tempo num trabalho de composição e recomposição incessante com a memória. A memória aqui não é entendida como um fator psicológico, mas como elemento ontológico - ela não é nem uma "reserva particular de um sujeito, nem se confunde com o mundo dos objetos. Ela é a condição mesma do sujeito e do objeto" (Kastrup, 2007, p. 27). Dentro dessa perspectiva, a invenção pode ser compreendida como um jogo, em duração, com a memória, no qual sujeito e objeto se coengendram e se codeterminam por meio de um trabalho em rede, um trabalho descentralizado de conexões entre elementos e estruturas diversas, que criam, por sua vez, regimes de funcionamento também múltiplos e inéditos.

$\mathrm{Na}$ criação das ações modulares do elástico e da mão esquerda, enfatizamos um aspecto do processo cognitivo: a percepção. De acordo com o filósofo estadunidense Alva Noë (2004; 2012), a percepção é um processo que se dá por meio do exercício e da compreensão sensório-motora e da relação que travamos com o objeto. Esse processo permite termos modalidades de acesso ao mundo e nos conectarmos com ele:

Coloco que a consciência perceptiva requer a operação conjunta da sensibilidade ao objeto e também o que chamo de compreensão sensório-motora. Penso a compreensão sensório-motora como uma espécie de compreensão em geral e por isso considero a percepção como dependente da operação de compreensão sensório-

${ }^{6}$ O filósofo francês Gilles Deleuze (2007, p. 72) traz a definição de sentido como relação paradoxal e o significado mais relacionado à ordem do conhecido, da não-contradição. Para Deleuze, "o interesse das determinações de significação é o de engendrar os princípios de não-contradição." 
motora enquanto exemplo de um fenômeno mais geral, invocado a título preliminar, de que a compreensão revela o mundo para nós. [...] A habilidade sensóriomotora opera (inter alia) a mesma função que a compreensão conceitual opera em humanos maduros: aquela de trazer o mundo ao foco e possibilitar nossa conexão a ele (por ambos: percepção e pensamento). (2012, p. 24, tradução nossa) ${ }^{7}$.

Diante disso, um trabalho que tem por base a pesquisa sobre os processos perceptivos também é um trabalho inventivo, pois o processo de invenção é um processo de criação de problemas que ocorre durante o próprio processo de percepção. Ou seja, enquanto se trabalha a percepção, ocorrem perturbações no próprio seio perceptivo que afetam e transformam o modo com que nos autopercebemos e o modo como percebemos o ambiente. Essas perturbações fazem com que a percepção se adapte e crie, invente novas maneiras de entrar em relação, novas respostas para essas novas configurações.

Ao considerarmos a influência dos processos de invenção nos modos de gestão do coletivo, e ao permitirmos que sua produção seja causa e efeito de tal processo, inauguramos uma política de relações que não ignora as fissuras perceptivas provocadas no artista no momento em que a ação vai se configurando e ganhando novos contornos, cuja consequência maior é a sua existência como potência de afeto quando posta em jogo, em relação com o público. Esse modo de atuação busca provocar fissuras perceptivas naqueles que vivenciam essa experiência de encontro. Assim, quando se articulam modos de existência e procedimentos artísticos contaminados por uma abertura às relações, tem-se também uma sucessão de novas possibilidades inventivas.

\section{Ação modular do elástico: emergência em políticas de relações}

Por cerca de um ano e meio, Paloma Bianchi trouxe sua pesquisa de mestrado para a experimentação junto ao Mapas e Hipertextos. Sua dissertação ${ }^{8}$ investigou como a Coordenação Motora, estudo desenvolvido pelas fisioterapeutas Marie - Madeleine Béziers e Suzanne Piret na década de 50 na França, pode operar como um dispositivo para a criação de poéticas no trabalho do coletivo. Nossa experiência sensório-motora molda o modo de conhecer, de perceber, de sentir, de conceituar tudo que nos cerca, é a partir dela que se desenvolvem os modos mais complexos de conhecer, perceber, sentir e conceituar o mundo (Béziers; Piret, 1992). Assim, a pesquisa junto ao coletivo questionava como um trabalho que investiga motricidade

a partir da experiência da anatomia e cinesiologia humanas pode ser levado a um processo de criação, em que as maneiras de conhecimento, de percepção, de sensação e de conceituação não são somente parte, mas constituem o próprio pro-

\footnotetext{
7 "I propose that perceptual consciousness requires the joint operation of sensitivity to the object and also what I am calling sensorimotor understanding. I think of sensorimotor understanding as a species of understanding in general, and so I think of the ways perception depends on the operation of sensorimotor understanding as exemplifying the more general phenomenon, invoked at the outset, that understanding discloses the world to us. [...] Sensorimotor skill plays (inter alia) the same function that conceptual understanding can play in mature humans: that of bringing the world into focus and enabling us to lock on to it (in both perception and thought)."

${ }^{8}$ Para mais informações ver a dissertação de mestrado de Paloma Bianchi (2016): Modos de ação, modos de percepção, modos de criação: o trabalho com a Coordenação Motora de Béziers e Piret como modo de ativação da percepção inventiva no processo de criação do coletivo Mapas e Hipertextos
} 
cesso.

Em meados de 2015, o coletivo começou a trabalhar um tipo de procedimento que não parte de uma ideia preconcebida e que não cria significado imediato. Queríamos construir procedimentos que pudessem ser seguidos e que, dessa obediência à regra, pudessem fazer emergir uma ação poética. Assim, começamos um experimento de improvisação tendo por base as qualidades que o trabalho com a Coordenação Motora pode trazer ao corpo em dança: as relações de apoios e de oposição; o jogo com o equilíbrio; o movimento perpétuo; a ação de sustentação; e a ação de resistência.

Tais experimentos faziam uso de um material específico: elásticos largos e longos fechados por um velcro forte o suficiente a ponto de sustentar o peso de um corpo sem rasgar ou abrir. Experimentamos diferentes configurações de uso do elástico. Num primeiro momento colocamos o elástico envolvendo quatro artistas e experimentamos caminhadas e corridas, assim como trocas de posição entre as artistas. Experimentamos também tirar o elemento elástico e manter a sensação que ele oferecia na movimentação que fazíamos. Por fim, encontramos uma configuração que parecia oferecer uma complexidade maior à movimentação e a possibilidade de emergência de situações diversas: quatro artistas, sendo que umas se ligavam às outras por elásticos distintos.

O trabalho que visa a emergência de algo é um tipo de procedimento típico da linguagem da dança que opera no sentido de ativar altos níveis de atenção e promover espaço para o processo inventivo. A noção de emergência (Stephan, 2004) advém dos estudos das ciências cognitivas e consiste na ideia de que a emergência só ocorre se a interação entre elementos diversos faz vir à tona algo que difere de todos os elementos e faz emergir um novo. Mas o que isso quer dizer? Pode-se pensar em termos de planos: em um plano básico encontram-se elementos diversos; quando esses elementos estabelecem relações entre si e se dessas relações decorre algo que não existia anteriormente há a emergência de um segundo plano. Esse segundo plano possui características que não existiam no plano básico: a interação entre elementos cria algo que não existia anteriormente em nenhum dos elementos. Tais características são irredutíveis - no sentido de que não podem ser decompostas - e imprevisíveis - no sentido de que não há como sabermos de antemão quais seriam as características emergentes da interação entre os elementos. A emergência possui uma qualidade efêmera e só ocorre enquanto um evento está em curso.

Ao transpormos essa noção de emergência para o trabalho desenvolvido na ação modular do elástico, podemos observar os elementos que a compõem - as artistas e os elásticos não contêm por si sós as características que a interação entre eles faz emergir. No entanto, quando a relação entre as artistas e o elástico se configura, pode-se observar a emergência de qualidades e de procedimentos na ação em curso. Dessa relação emergiram diferentes desenhos de restrição. Percebemos que, para conseguirmos nos manter ligadas pelos elásticos, deveríamos nos manter fora do eixo, notamos que o peso do corpo era aquilo que indicava a direção a ser tomada e percebemos que a tração proporcionada pelo elástico era o motor para o movimento. Dessas características emergentes também surgiram outras qualidades: o jogo com o equilíbrio; o trabalho com a força; as torções; a resistência; o movimen- 
to ininterrupto. Todas essas características irredutiveis e imprevisíveis que emergiram da interação entre os corpos e os elásticos foram identificadas e acolhidas por nós e desenharam o modo de conduta dessa ação modular.

Ainda assim, percebemos que faltava outro elemento que pudesse nos deixar em uma situação de menos controle sobre o que pudesse ocorrer, e optamos, então, por utilizar vendas durante a ação. A venda trouxe às artistas uma qualidade de atenção aos mínimos movimentos que ocorriam e uma autopercepção muito intensa. Trouxe, também, o risco, pois vendadas não conseguiam saber onde exatamente estavam em relação ao espaço e ao público presente.

A ação modular do elástico foi apresentada em três diferentes ocasiões ${ }^{9}$, nas quais a mesma estrutura se manteve. A ação se inicia com a entrada das quatro artistas, que se posicionam, uma de cada vez, numa postura de desequilíbrio. A primeira entra sem nenhum elástico e se posiciona. A segunda entra com um elástico nas mãos, coloca o elástico na artista que está no espaço, coloca o outro lado do elástico em si mesma e também se posiciona. A terceira age da mesma forma: ao entrar coloca o elástico na segunda artista que entrou, coloca o outro lado do elástico em si mesma e se posiciona. A quarta artista entra com dois elásticos, coloca um elástico na terceira artista e em si mesma, coloca outro elástico na primeira artista e em si mesma, e se posiciona. Outras duas artistas vendam as quatro e se colocam nas laterais, a fim de proteger o público de possíveis acidentes.

A movimentação se inicia com o acolhimento do desequilíbrio que a própria postura oferece. A partir daí se desenvolvem situações que podem ser de movimento lento; pausas; movimentos rápidos e contínuos; quedas e recuperação. O que ocorre a cada vez que a ação se realiza é imprevisível; as negociações entre as artistas e a tração dos elásticos se dão no aqui e agora da ação, tornando impossível que se anteveja um caminho a ser seguido ou um fim predeterminado. Justamente por essa ação não ter um fim determinado pela própria movimentação, ela termina com as artistas que protegem o público retirando os elásticos um a um.

${ }^{9} \mathrm{~A}$ ação modular do elástico foi apresentada no dia 25 de setembro de 2015, durante a Semana Performática, no SESC Prainha (Florianópolis-SC); na Mostra BRECHA, dia 10 de outubro de 2015, no Micro Centro Cultural Casa Vermelha (Florianópolis-SC); no dia 11 de dezembro, no Festival Didascálico no Instituto Federal de Santa Catarina. 
Figura 1: Ação modular do elástico

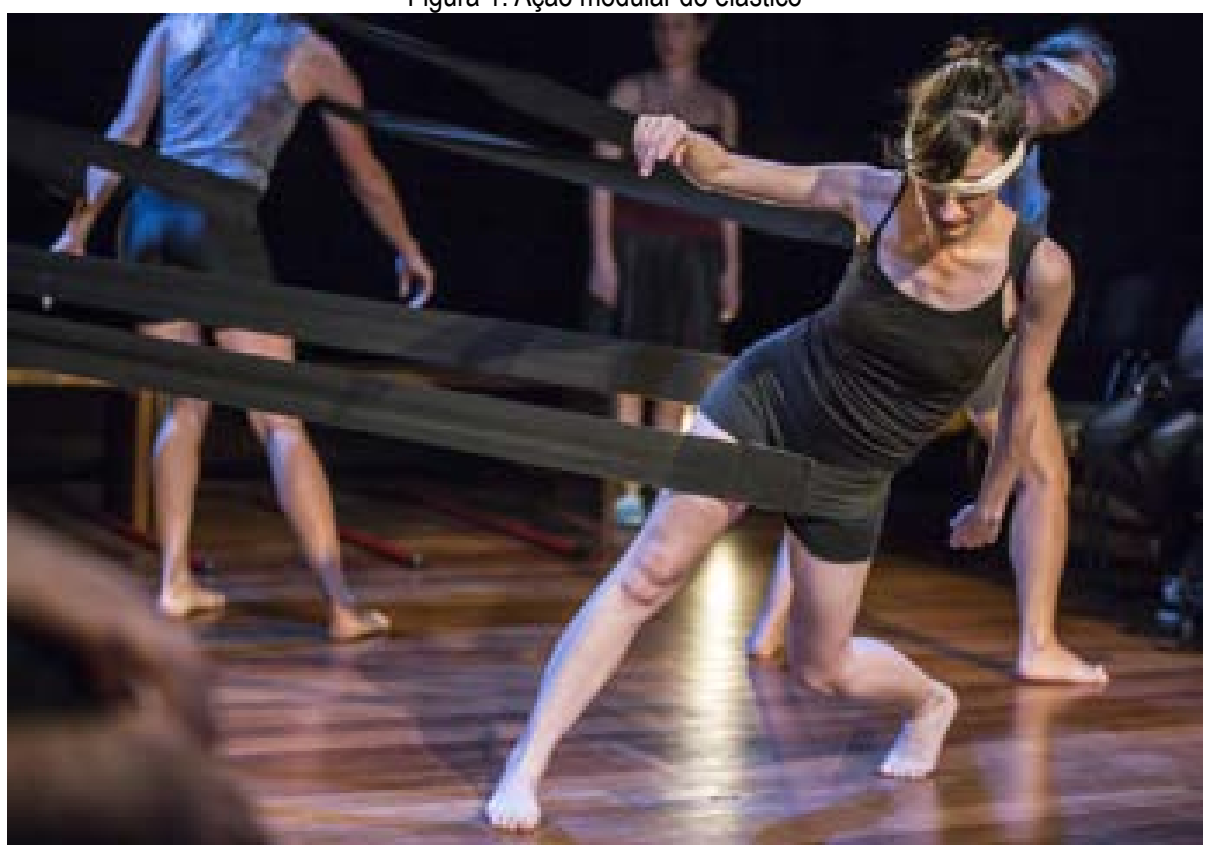

Sem Cabimento, realizado no dia 25 de setembro de 2015, no SESC Prainha (Florianópolis/SC). Foto: Cristiano Prim

Ao longo dos ensaios e das apresentações dessa ação percebemos algumas características que fazem emergir alguns possíveis sentidos. A artista do Mapas e Hipertextos Diana Piazza (2015, informação oral $)^{10}$ diz que o equilíbrio se encontra não em cada um dos corpos, mas nas relações entre os corpos. Diana Gilardenghi (2015, informação oral) ${ }^{11}$, também integrante do coletivo, comenta que o trabalho de oposições é o que permite que nos mantenhamos em constante jogo de movimento. Já Jussara Belchior (2015, informação oral) ${ }^{12}$ chama a atenção para o fato de que, em vez de normatizarem a movimentação dos corpos, em vez de criarem um modo de movimentação padronizado, os desenhos de restrição evidenciam a singularidade de cada uma das artistas, seus modos de se mover, seus modos de resistir, seus modos de sucumbir.

Acreditamos que a ação modular do elástico inaugura uma política própria em seu processo de produção. A atenção aos procedimentos e o refinamento da escuta exigidos das artistas fizeram emergir um tipo de percepção que estava no todo, criando um plano comum que deve ser gerido e sustentado no aqui agora, uma política inventiva negociada de acordo com as relações que ocorrem naquele momento específico, de acordo com aquele contexto particular.

Demos tempo ao trabalho, insistimos na experiência sem nenhum objetivo traçado de antemão, deixamos que as estruturas emergissem pela própria experimentação com o material que escolhemos trabalhar. Foi um exercício grande de percepção: de autopercepção, de percepção do outro, de percepção do ambiente e de percepção do que emergia no aqui agora. Kastrup (2007) diz que o processo de invenção requer uma duração no tempo e uma constante experiência, uma prática ininterrupta, com aquilo que existe. O que existe, a estrutura que há, já possui características condicionantes, mas tais características não são deterministas, dependem dos modos de interação, que são circunstanciais e inantecipáveis.

${ }^{10,11,12} \mathrm{Em}$ conversa informal. 


\section{Ação modular mão esquerda: políticas de relações em emergên- cia}

A primeira proposição de trabalho de Raquel Purper dentro do coletivo relacionou-se à ideia de uma política de subjetivação ${ }^{13}$ e partiu de um texto retirado da internet $^{14}$, que apresenta a relação de uma dançarina com a mancha de nascença presente em seu rosto. A matéria pareceu ser o mote ideal para começar a experimentar a criação a partir da reflexão sobre a subjetividade: como é conviver com marcas pessoais que nasceram com você e que te constituem como sujeito no mundo?

A partir da leitura da matéria, Raquel solicitou que as artistas do coletivo escrevessem aquilo que mais havia chamado a atenção, como um roteiro pessoal para consulta, no intuito de selecionar quais os elementos do texto que poderiam auxiliar na criação de uma pequena ação, que seria requisitada logo em seguida. Desse ensaio surgiu, na criação proposta por Cecília Lauritzen, a frase que foi, posteriormente, o mote da ação modular da mão esquerda: "eu não deixaria minha filha escrever com a mão esquerda pois isso é coisa do diabo". Cecília, ao realizar a sua ação, criou uma resistência imaginária que não a deixava escrever com a mão esquerda.

No ensaio seguinte, Raquel propôs uma improvisação a partir da relação entre a mão esquerda e a escrita. Nesse dia, Cecília trouxe uma resistência real auxiliada pelo uso de um elástico amarrado em sua mão esquerda. Raquel pediu para que uma das artistas manipulasse o elástico no sentido de impossibilitar a escrita de Cecília. No desenrolar da improvisação, outras artistas participaram com ações diversas, mas sempre com o objetivo de impedir Cecília de escrever com a mão esquerda.

No encontro seguinte reunimos diversos materiais (rolo de papel craft, rolo de papel higiênico, papéis em geral, caneta, pincel, giz de cera, espuma de barbear) no intuito de serem eles usados tanto para auxiliar como para obstruir a escrita de Cecília. Surgiu também a vontade de usar luvas de limpeza amarelas, pois nos remetiam à sensação de contaminação. Após esses procedimentos, Raquel propôs uma improvisação em que cada uma das artistas ocupava um papel: uma das artistas comentava e julgava as ações de Cecília; outra artista caminhava em cima das folhas de papel ofício que estavam no chão; as outras tentavam perturbar Cecília usando objetos. Uma atmosfera de opressão começou a se delinear, em que se revelava a presença de um opressor e de um oprimido. Dentre todas as ações realizadas na improvisação, algumas foram selecionadas para serem aprofundadas: a ação da artista que caminhava pelas folhas; a ação vocal que oprimia constantemente Cecília, dizendo coisas como "a letra está pequena", "faz de novo", "escreve mais redondo", "fecha as pernas"; as várias maneiras de aprisionar a mão esquerda; a ação de amarrar a mão esquerda à perna; o carinho que Cecília fez na perna de uma das artistas a fim de seduzir quem a estava oprimindo. Num outro encontro, produzimos um jogo em que todas as artistas tentavam impedir que Cecília escrevesse com a mão esquerda. A ideia era a de desenvolver um cerceamento em conjunto. Descobrimos que Diana Piazza e Paloma Bianchi também são canhotas e Raquel sugeriu que ambas assumissem o papel de

${ }^{13}$ Segundo Michel Foucault (1993), os modos de subjetivação são as escolhas estéticas e políticas por meio das quais se acolhe um determinado tipo de existência.

${ }^{14}$ Disponível em: http://entretenimento.r7.com/mulher/fotos/dancarina-de-22-anos-se-recusa-a-fazer-cirurgia-de-remocao-de-marca-de-nascenca-24032015\#!/foto/1 
opressoras de Cecília, evidenciando que, muitas vezes, o opressor é ou já foi o próprio oprimido.

Estávamos ensaiando há algum tempo e já tínhamos um esboço dessa ação. Como o coletivo reúne um grupo de pessoas bastante ativo e crítico, quando as ideias surgem, elas não são somente experimentadas, mas também problematizadas, e foi isso que ocorreu. Sabíamos que estávamos em um caminho interessante, mas identificamos que o que emergia no processo, como desenho da ação, poderia ser potencializado se permitíssemos uma maior contaminação de informações do nosso entorno, das questões que influenciam nossa vida em sociedade. As manifestações contra o atual governo começavam a ganhar força e revelar suas incoerências, seus absurdos, a falta informação e a defesa de interesses de um grupo específico de pessoas. As camisetas da CBF tomavam conta das manifestações contra a corrupção, algumas pessoas pediam a volta do governo militar, outras afirmavam que o Brasil vive sob uma ditadura comunista bolivariana. Percebemos que o clima sócio-político se assemelhava muito às brigas entre times de futebol rivais. Milene havia vivenciado alguns momentos das mobilizações de direita em São Paulo, e, segundo sua descrição, o encontro entre os grupos nas estações de metrô fora marcado por gritos agressivos direcionados à presidente Dilma, acompanhados de vuvuzelas e outros objetos sonoros, gerando um ambiente ao mesmo tempo de afirmação de coletividade e de intimidação.

Em um dos ensaios, após uma dessas manifestações, percebemos a necessidade de englobar, de algum modo, as questões que nos tomavam naquele momento. Assim, o processo foi se contaminando pelos acontecimentos mais recentes, e a cada ensaio tínhamos um dado novo a acrescentar. Um mapeamento de frases sem nexo, contraditórias, e muitas com teor fascista retiradas das faixas empunhadas nas manifestações foi incluído na ação. Cecília, a canhota aprendiz, era obrigada a escrevêlas de acordo com a escolha de Paloma, a canhota opressora, de Raquel, que fazia a análise gramatical das frases, junto ao público. O público também era convidado a sugerir frases do mesmo teor. Passamos a explorar várias formas de opressão: dividíamos o público entre destros e canhotos; colocávamos o público canhoto a registrar em escrita ou em desenho a situação vivenciada ali; a canhota aprendiz era corrigida, amarrada, torturada, sem chance de se defender. O público se transformou em cúmplice e em vítima da opressão e do poder.

A ação modular mão esquerda foi apresentada em quatro ocasiões ao longo de 2015. Sua política de invenção foi sofrendo alterações todas as vezes em que foi apresentada. Na primeira vez que foi colocada em relação com o público ${ }^{15}$, ela se iniciava com Milene colocando no espaço os objetos que seriam usados durante a ação, de modo extremamente organizado: Milene alinhava as folhas de papel ofício com precisão; dispunha canetas milimetricamente alinhadas às folhas; e colocava fitas coloridas que posteriormente serviriam para amarrar Cecília. Logo depois, Milene pedia aos destros do público que se dirigissem para o outro lado do espaço (a frente da ação foi trocada). Após os destros estarem bem acomodados, outra artista chamou os canhotos e ordenou que eles também trocassem de lugar. Além disso, pediu para

${ }^{15} \mathrm{Na}$ Mostra XOKE de Performance da Casa Vermelha, espaço mantido por coletivos de artistas, realizada em 7 de junho de 2015. 
que um dos canhotos (neste dia havia 3) sentasse em um local reservado, entregou a ele uma prancheta com uma folha em branco e pediu a ele que descrevesse a cena que iria acontecer em seguida, mas com a mão direita.

Logo após essa introdução, Milene se posicionava ao lado de cada uma das artistas e levantava cartazes que identificavam com que mão cada uma das artistas escreve: Cecília escreve com a mão esquerda; Diana escreve com a mão esquerda; Paloma escreve com a mão esquerda. A última folha identificava a própria Milene: eu escrevo com a mão direita. Enquanto Milene levantava as folhas, Diana e Paloma, ajoelhadas em frente a uma folha, colocavam luvas amarelas em suas respectivas mãos esquerdas. Em seguida, Milene colocou-se também em frente a uma folha e, assim, as três escreveram a seguinte frase: "minha mãe não deixaria minha filha escrever com a mão esquerda, pois isso é coisa do diabo". Durante a ação, Raquel percebeu que Diana escrevia com a mão direita, e não com a mão esquerda, como estava explicitado na folha. Quando questionada sobre tal atitude, a artista respondeu que não conseguia mais escrever de forma legível com a mão esquerda e que, depois de anos, aprendeu, de fato, a escrever com a mão direita. Isso fez Raquel pensar que, em uma próxima apresentação, seria melhor escrever na folha: "Diana escrevia com a mão esquerda".

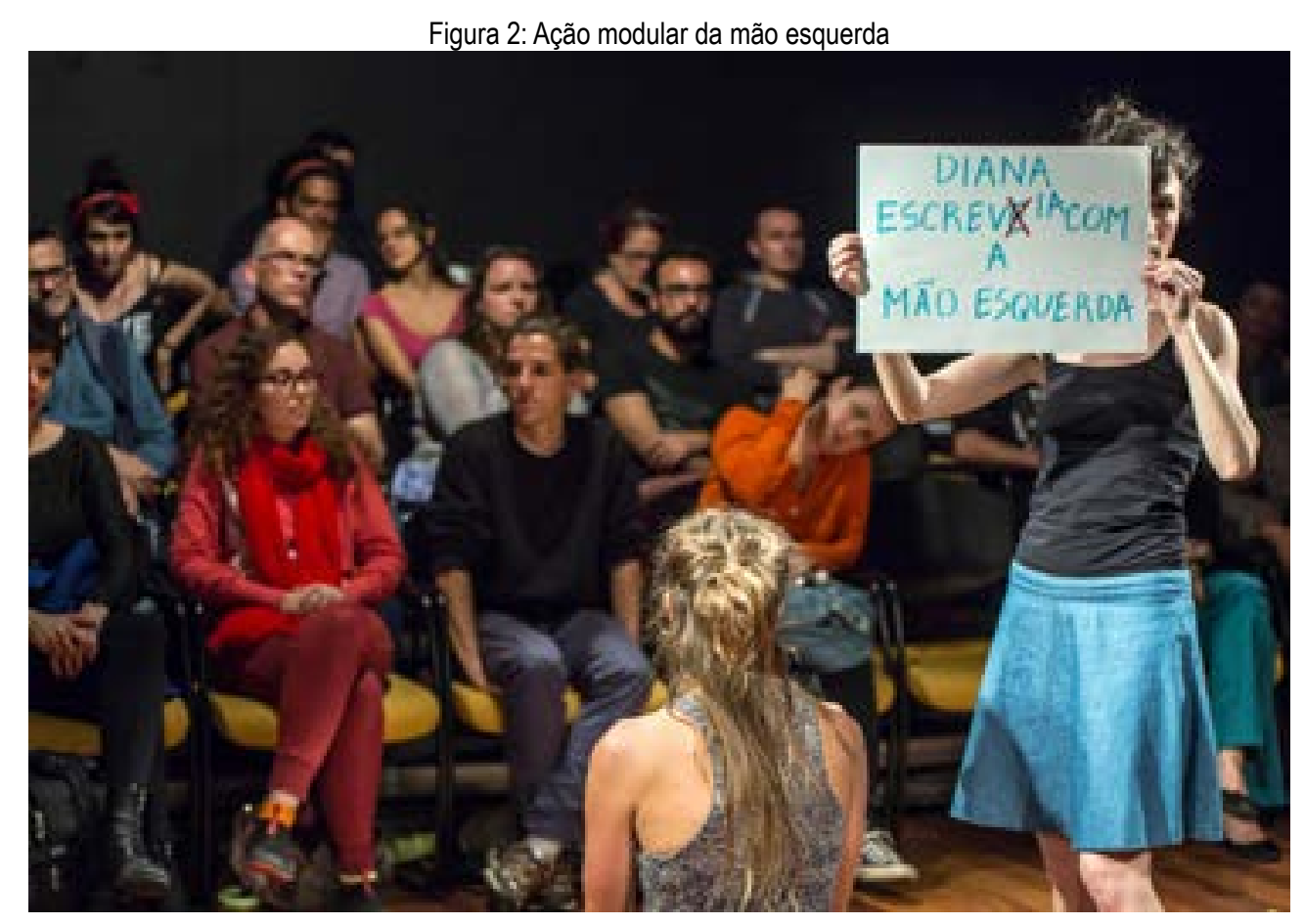

Sem Cabimento, realizado no dia 25 de setembro de 2015, no SESC Prainha (Florianópolis/SC). Foto: Cristiano Prim

Após a escrita, elas levantaram as folhas mostrando as frases para o público e, logo em seguida, chamaram Cecília (que estava ao fundo do local da ação) e mostraram a frase a ela também. Em seguida, Diana Piazza vai em direção a Cecília com o objetivo de colocar a luva amarela em sua mão esquerda. Cecília, por sua vez, deseja se apossar de uma folha e de uma caneta para escrever algo. Acontece um jogo corporal intenso entre as duas até que Diana Piazza consegue colocar a luva amarela na mão de Cecília. Cecília, então, vai em busca dos objetos que necessita para escrever 
e se aproxima de Milene - a guardiã das folhas e canetas -, que se encontra deitada sobre elas. Cecília deita a seu lado e tenta agarrar a folha com seus pés e mãos. Quando ela alcança a folha, Paloma intervém ordenando que ela devolva a folha ao lugar. Porém, as tentativas de Cecília continuam até que ela consegue apreender uma folha e uma caneta. Quando ela está em condição de escrita, Paloma interrompe a ação e pergunta a Milene o que Cecília poderia escrever, ao que ela responde: "Eu preciso aprender a escrever bem com a mão direita". Paloma sugere que Cecilia escreva a frase em espanhol. Cecília inicia a escrita, mas Paloma a impede dizendo que ela escreve muito lentamente.

Milene então sugere outra frase: "Minha esperança está em Deus e nos verdadeiros militares de direita". Paloma pergunta a Raquel sua opinião, ela responde que a frase está bem construída, pois tem sujeito, verbo de ligação e complemento nominal. Insatisfeita, Paloma pede outra frase. Milene propõe: "Feminicídio sim, fomenicídio não. Fora PT". Paloma diz que a frase é ótima, pois é completamente sem cabimento, e ordena que Cecília a escreva. Milene oferece uma nova frase: "Intervenção Constitucional Militar em Cristo". Paloma pede novamente a opinião de Raquel, e ela responde: "Esta frase tem um problemão. Cristo. Cristo não é advérbio de lugar, então não há como existir uma intervenção 'em Cristo'". Cecília, então, diz que quer mostrar uma frase que preparou. Paloma pergunta ao público se ele quer ver. As pessoas respondem que sim. Cecília levanta a folha alto com os dizeres: "Mãe, eu sou da direita ou da esquerda?".

Muitas transformações na ação da mão esquerda aconteceram neste breve período de um mês entre duas apresentações. Na Mostra Paralela Brecha, realizada em 17 de outubro de 2015, a mão esquerda, que era a ação final do Sem Cabimento, passou a ser a ação inicial. Para que isso ocorresse, o início, nas duas apresentações subsequentes, passou a acontecer em um outro espaço (hall da Casa Vermelha e pátio coberto do IFSC). Antes de adentrar em determinado espaço fechado para começar a mão esquerda, o público era dividido entre destros e canhotos. Os destros tinham permissão para entrar no local fechado, enquanto os canhotos aguardavam do lado de fora. Nesse momento, as três artistas canhotas encontravam-se, também, do lado de fora. Elas pedem que os canhotos participem da ação. Ao entrarem na sala, eles se deparam com folhas de papel e canetas no chão. Cada um tem um lugar marcado para sentar em frente a uma folha de papel. Depois que todos estão sentados (as três artistas canhotas e os canhotos participantes da ação), três artistas destras entram e se colocam atrás das canhotas. Uma das destras levanta uma folha de papel bem acima da cabeça da canhota com o escrito: "Cecília escreve com a mão esquerda". A outra destra levanta outra folha de papel: "Diana escrevia com a mão esquerda". Por fim, a terceira destra levanta mais uma folha de papel: "Paloma deveria escrever com a mão esquerda". As destras, então, levantam, juntas, cada uma a sua folha, nas quais está escrito: "Eu escrevo com a mão direita". Elas, então, se afastam e uma delas levanta uma última folha perto dos canhotos participantes: "Eles escrevem com a mão esquerda". A partir daí, uma gravação em off é disparada:

"Atenção, canhotos! Prestem atenção às instruções e sigam os passos com precisão (repete a frase). Levante a sua mão esquerda na altura do peito mantendo o braço alongado. Flexione o seu cotovelo esquerdo a noventa graus, levando os de- 
dos da mão alongados apontando para o teto. Pegue a luva amarela com sua mão direita. Insira cuidadosamente em sua mão esquerda. Certifique-se que cada dedo se encontra em seu devido lugar. Pegue a caneta que está ao seu lado e prepare-se para escrever. Vou ditar: 'Eu não deixaria minha filha escrever com a mão esquerda, pois isso é coisa do diabo' (repete a frase). Levantem suas placas na altura do rosto e mostrem para a plateia (pausa). Poderia estar melhor escrito".

Após a gravação, Paloma levanta-se e diz: "Vamos começar a humanização". Pede para que Diana Piazza e Milene assumam seus postos e, em seguida, dirige-se aos canhotos, solicitando que virem suas folhas do avesso e dando a eles duas opções: descrever ou desenhar a ação que vamos realizar, só que com a mão direita. $\mathrm{E}$ assim a ação se desenvolveu de forma similar à que já havíamos feito. Paloma pergunta a Milene o que Cecília vai escrever e, assim, Milene começa a sugerir frases: "Feminicídio sim, fomenicídio não", em inglês; "Pobres, usem camisinha". Paloma pergunta a Raquel sua sugestão, ao que ela responde que a frase é muito bem construída, pois tem um vocativo separado por vírgula, verbo e objeto direto; "Anistia nunca mais. Tortura somente na hora certa. Brasil, ame-o ou deixe-o". Paloma gosta, mas acha a frase longa e escolhe somente a frase do meio: "Tortura somente na hora certa". No exato momento em que Cecilia escreve essa frase, Diana Piazza a está amarrando de forma circular e forte com as fitas, passando, inclusive, fitas pela boca. Outras frases proferidas foram: "Não gosto muito de calor, nem de frio. Zero grau para mim está perfeito" - frase enunciada por uma modelo, repórter e apresentadora brasileira; e "O Brasil deveria desistir desta bobagem de ter uma cultura. Ninguém iria notar a falta".

Novas frases vieram a fazer parte da ação quando a apresentamos no Festival Didascálico, no Instituto Federal de Santa Catarina, em 11 de dezembro de 2015, tais como: "Mariana embaixo da lama, Deus quis assim"; "Somente seis pessoas sofrem com a crise econômica no Brasil: eu, tu, eles, nós, vós, eles"; "Professor que falar de política e de gênero em sala de aula vai preso". Pensamos em explicitar assuntos relativos à educação, já que estaríamos em uma instituição de ensino, mas sempre atentas às notícias que bombardeavam o País naquele momento.

A canhota-aprendiz recebe lições da destra obediente à canhota-opressora, que é, por sua vez, espelhada pela ex-canhota. Abuso de poder, violência, tortura, adequação aos padrões sociais vigentes, incoerências na vida social, nas relações políticas, e os graves efeitos da falta de investimento em educação - são temas abordados nessa ação em que ser canhoto é pertencer a uma parcela da população que deve ser recuperada por meio de uma educação normativa e incisiva. A canhota-aprendiz nunca realizava a tarefa a contento e, por isso, era humilhada e torturada. Eram necessárias muitas frases para que ela treinasse sua destreza. A análise gramatical desviava o foco do teor absurdo das frases. Quando o público era dividido para realizar tarefas - como descrever as ações seguindo o imperativo da opressora, ou decidir qual frase a oprimida deveria escrever -, ele se tornava cúmplice da ação, seja oprimindo ou tomando o lugar do oprimido. O público é levado a tomar um posicionamento político, uma vez que a situação o convocava a um engajamento distinto caso houvesse outra relação espacial ou outra relação exigente de um menor nível de participação. A política não estava somente no tema, mas também no posicionamento convocado por uma ação artística impregnada pela política das relações. 


\section{Considerações}

Os modos de existência e re-existência do coletivo Mapas e Hipertextos, as experiências de concepção e os atos de colocar as ações em relação com o público são conectados, principalmente, pelos aspectos relativos às duas noções de política que abordamos neste artigo. Buscamos um modo de funcionamento menos hierárquico e mais democrático, experimentando formas de potencializar as relações entre os integrantes do coletivo e entre artista e público. Isso se deve à tentativa de não adesão à noção de política-poder, como exposta por Latour (2004), e ao desejo de identificar possíveis contaminações desse modo de proceder nas relações sociais. Movemo-nos por um constante mapeamento de situações que reverberam no âmbito coletivo, buscando referências em aspectos da vida em sociedade, enfatizando suas contradições e idiossincrasias. Trata-se, aqui, de uma produção que acontece não somente na escolha de um tema que preceda a produção em arte, mas na política da invenção de procedimentos que ora surgem de um tema, que carrega a noção de significado, como exposta por Deleuze (2007); ora são geradores deste, considerando os possíveis sentidos emergentes da relação com o público.

Identificamos, nesse processo, que o político está tanto no modo de composição em artes presenciais quanto no tema abordado, a exemplo do que ocorre na ação modular da mão esquerda, que trata do poder político federativo brasileiro. Desenvolvemos um modo de fazer que permite uma contaminação pelo contexto e que tem a política das relações como procedimento e o político como enunciado. Apesar de se tratar de dois fragmentos compositivos, com durações entre dez e quinze minutos cada um, tal experiência nos ofereceu parâmetros para a estruturação de outro elemento determinante das operações do Mapas e Hipertextos: a constante investigação da relação entre os modos de fazer em artes presenciais e os modos de vida em sociedade.

\section{Referências}

BUELA, Alberto. Teoria do dissenso. 2011. Disponível em: http://legio-victrix. blogspot.com.br/2011/10/teoria-do-dissenso.html. Acesso em: 28 abr. 2016.

DELEUZE, Gilles. Lógica do sentido. Trad. Luiz Roberto Salinas Fortes. São Paulo: Perspectiva, 2007.

EUGÉNIO, Fernanda; FIADEIRO, João. Secalharidade como ética e como modo de vida: o projeto AND_Lab e a investigação das práticas de encontro e de ma nuseamento coletivo do viver juntos. Urdimento - Revista de Estudos em Artes Cênicas / Universidade do Estado de Santa Catarina. Programa de Pós-Gradua 
ção em Teatro, Florianópolis, vol. 1, n. 19, p. 61-69, nov. 2012.

BÉZIERS, Marie-Madeleine; PIRET, Suzanne. A coordenação motora: aspecto mecânico da organização psicomotora do homem. São Paulo: Summus, 1992.

FOUCAULT, Michel. Verdade e subjetividade. Lisboa: Cosmos, 1993.

KASTRUP, Virgínia. A invenção de si e do mundo - Uma introdução do tempo e do coletivo no estudo da cognição. Belo Horizonte: Autêntica, 2007.

LATOUR, Bruno. Políticas da natureza: como fazer ciência na democracia. Trad. Carlos Aurélio Mota de Souza. Bauru: EDUSC, 2004.

NOË, Alva. Action in perception. Cambridge: MIT Press, 2004.

NOË, Alva. Varieties of presence. Cambridge: Harvard University Press, 2012.

RANCIÈRE, Jacques. A partilha do sensível: estética e política. Trad. Mônica Cos ta Netto. São Paulo: Ed. 34, 2005.

STEPHAN, Achim. Phenomenal emergence. Networks, n. 3-4, p. 91-102, 2004.

SCHIOCCHET, Michele Louise. Performance art como forma de resistência: dos espaços alternativos de Nova York à superidentificação. Tese (Doutorado em Teatro), Universidade do Estado de Santa Catarina (UDESC), Florianópolis, 2015. 